\title{
Borderline Personality Disorder, Lived Space, and the Stimmung
}

\author{
Fabian Lo Monte ${ }^{\mathrm{a}, \mathrm{e}}$ Jérôme Englebert ${ }^{\mathrm{b}, \mathrm{c}, \mathrm{d}}$ \\ ${ }^{a}$ Department of Psychology, University of Liège, Liège, Belgium; ${ }^{b}$ Centre de Recherches: Pénalité, Sécurité \& \\ Déviances, University of Brussels, Brussels, Belgium; ' ${ }^{C}$ Centre de Recherche Interdisciplinaire sur la Déviance \\ et la Pénalité (CRID\&P), University of Louvain, Ottignies-Louvain-la-Neuve, Belgium; ${ }^{\mathrm{d} C e n t r e ~ d e ~ R e c h e r c h e s ~}$ \\ Phénoménologiques, University of Liège, Liège, Belgium; 'Clinique Notre-Dame des Anges, Liège, Belgium
}

\section{Keywords}

Borderline personality disorder · Ecstasy · Elation · Ecology · Immediacy · Lived space · Phenomenology · Reflexivity · Stimmung · Topology · Ubiquity

\begin{abstract}
Most articles and theories about borderline personality disorder (BPD), either in the psychoanalytical field or the cognitivist one, explicitly or implicitly inscribe themselves in a topographical framework that either carry a fundamental representationala prioriorgive prominencetocausal explanations. Less is written about the phenomenological everyday lifeworld of borderline people. This article aims to contribute to the description of such a world. Drawing upon clinical sequences that give prominence to the first-person perspective, we will analyse the experience of some typical "symptoms" of BPD in a phenomenological and topological way. We will be led to conclude that the borderline stimmung seems to display the following characteristics: a pervading immediacy of lived experience, a territorialization that tends towards ubiquity, a certain difficulty to deal with the unity and difference poles, a quite horizontal concern with ecstasy and elation, and a waning of reflexivity in the lived space.
\end{abstract}

(c) 2022 S. Karger AG, Basel

\section{Introduction}

In this article, we will try to explore some of the typical "symptoms" in borderline people by adopting an offbeat viewpoint. Leaning on some excerpts of clinical cases, we will unfold the experience of some "typical" phenomena that occur in borderline people's life, and we will analyse it and reinterpret it phenomenologically.

For each "symptom," a brief introduction will remind some important historical, theoretical, and clinical thoughts. Then, an alternation will take place between clinical excerpts and bits of phenomenological analysis. A metacommentary will intervene at the end of each section in order to summarize our thoughts; it will act as an intermediary conclusion and will aim to progressively build cross-sectional links between the successive conceptual developments. In that way, proceeding from an inductive methodology, we will come to portray the composite stimmung or emotional atmosphere that is associated with the so-called symptoms and that will eventually come out as a global insight.

Given the inductive nature of our study, the theoretical notions that will emerge from our analyses will directly take root in the clinical sequences. Therefore, they will be developed throughout our article rather than being pre-

\footnotetext{
Karger"
}

Correspondence to:

Fabian Lo Monte, fabian.lomonte@uliege.be 
liminarily developed. However, it seems necessary to present the frame in which the developed concepts will take place, given that this frame will permeate the entirety of our thoughts.

\section{Various Paradigms of Space}

There are different ways of apprehending space in psychology. Among these different frameworks, the first paradigm is the topographical one [1]. This paradigm is an allegorical and metaphorical viewpoint of space. That consists in using space as a mean of representation. This framework leads to theoretical constructivism. For instance, in Freudian theories, the "psychic apparel" is depicted in a spatial way, by means of schematic figures that pave the way for some distinctions between "partial psychic systems" (e.g., id, ego, and superego or unconscious and preconscious-conscious):

"We admit that psychic life is the function of an apparel to which we assign a spatial expanse, and that we suppose being composed of several parts. We then figure it as a sort of telescope, microscope or something of this kind.” ([2], own transl.)

These partial psychic systems themselves are located in a theoretical architecture. Another example of the use of space as a means of representation is given by some ways of considering traditional psychoanalytical diagnostic 'structures' in the nosography. For instance, Cancrini [3] proposes naming the borderline way of functioning an "ocean between 2 continents." This "ocean" and these "continents" are not material spaces; they are imagined ones. Space is embedded in thinking and language, which are primary.

When it comes to studying human experience, this viewpoint invites us to implicitly emphasize the delineation between inner and outer spaces. It tacitly introduces the idea that there are an inside world and an outside world, considering the bodily surface as the very boundary between these 2 worlds. Thanks to the psychoanalytical legacy, borderline-related experiences have abundantly been studied according to a topographical framework. That is why, despite the clinical and theoretical relevance of this viewpoint, our contribution will essentially be inscribed in an adjunctive and complementary topological framework of space [1]. What does it mean?

The topological viewpoint focuses on material (or geometrical) space. At first sight, it seems to focus on the subjective appropriation of such a physical space by the person [1]. In other words, in contrast to the topographicalviewpoint, and in line with Bachelard [4] and Minkows$\mathrm{ki}$ [5], the topological viewpoint brings to the fore the continuity between what is traditionally defined as "ex- ternal" and "internal" realities or between "subject" and "object" as separated entities. Hence, this viewpoint leads to observation in order to study the being-situated. This way of considering space is reflected in what is generally called lived space by various phenomenologists [4-9]. It enables to consider territory in its existential and ecological aspects. In that, we need to point out that this type of spatiality is as much concerned with sociality and relational concerns as it is with the self.

As the reader will have realized, it could seem that the topological paradigm, in response to the reification of the inner world in psychoanalysis (or even in cognitivism [10-12]), tends in turn to reify external space. In fact, we generally think we should go beyond the "opposition" between 2 such paradigms. Given that the point is to fully adapt our study to the experiencing of people, we will seek to establish some premises that are in line with the ones of the daily experience. We will refer to Blaize [13]: "What is first is the experiencing (... i.e.,) the whole of the field organism/environment" (own transl.). Consequently, the organism as an individual, understood with his inwardness and the "mental space" as it may be figured in a topographical framework or as it is pointed when a person talks about "what is happening in his mind (or brain)," is included in such an experiencing. In fact, we think it should be considered as a part of what we mean by lived space, as well as, with Merleau-Ponty [6], scientific formalization could be included in the original lived experience which is the object of phenomenology.

Therefore, in line with Lewin's [14] precursory work and the Behaviour $=f$ (Person.Environment) equation, the fundamental prejudice of our topological viewpoint will be the entirety of the experiencing, involving both and simultaneously the organism and the environment. This will involve studying borderline experience as a way of inhabiting oneself and the world. This means that, in the last analysis, what will determine our study of lived space the most is what Fuchs [9] calls the "experienced phenomenal field." We will try to approach it by means of first-person reports and some observations.

That is why we can write that our contribution will be inscribed in a study of the being-in-the-space as a modality of the consciousness and of the being-in-the world. As such, our study will try to overcome "the still prevailing idea of an inner psyche and a corresponding individualistic view of psychopathology" [9].

\section{Phenomenological Concepts}

All these premises bring us to mention 2 key concepts. The first is the stimmung. Taking the phenome- 
nal field of the experiencing as our first and foremost prerequisite leads us to the characterization of the space in terms of emotional atmosphere. Therefore, referring to the stimmung, that the phenomenological tradition defines as an "affective tonality" and as an a priori structure of the human existence, is essential [15]. More recently, Bégout [16] focused on the concept of ambience. He outlined the tacit and hardly notable dimension of this emotional disposition: Bégout writes that from the moment we are existing in the world, we are situated in a particular affective way. These various terms (stimmung, atmosphere, and ambience) evoke a quite unique phenomenon. Leaving aside the linguistic and translation concerns, the fact that this phenomenon is difficult to define is probably linked to its intrinsically pre-reflexive nature.

The second concept is the lived distance, that can be traced back to Minkowski's [5] work. Again, considering the intrinsic intertwining between the organism and the environment and its stimmung logically leads to seize lived distance as a concrete tool that will inform us about this stimmung. Minkowski [5]:

"By affirming the 'me-here-now,' I affirm it in relation to an ambient becoming, distant from it, separated from and close to it by this sphere of ease in which life can come out" (own transl.).

These 2 concepts will act as overarching ones, in that, they will be omnipresent either in an explicit or in an implicit manner. They are likely to act softly or as baselines, given that our proposition will be a matter of precisely characterizing how they are expressed in the case of the borderline experience. In consequence, we will be led to produce, by the clinical analyses, other notions (e.g., immediacy or elation) to know the shapes that are taken by the emotional atmosphere and by the distance that unifies the person and the world. The stimmung will be the object we will seek to characterize, and the lived distance, a variation of it that will also serve as a concrete tool for its description. The notions that will emerge from the analyses will define the characteristics of the stimmung and, as such, will be our results.

\section{Preliminary Note about Diagnosis}

As far as the borderline question is concerned, the nosographical issue is a crucial one since borderline-related terms often resemble catch-all ones in clinical practice and since different theoretical systems have endowed these with various meanings. Nevertheless, this debate exceeds the scope of this contribution.

Borderline Personality Disorder, Lived Space, and the Stimmung
Taking a brief look at the nosography concern, we can notice that DSM-V [17] exceptionally established criteria that relatively fit with first-person experience of borderline people. Nevertheless, it seems that we are missing a gestalt, made of some organizers that would provide intuitive units of meaning for the comprehension of these people's experience.

That is why we will join Ratcliffe and Bortolan [18] in the way we situate our contribution in relation to the nosography. That is to say, we will inscribe our study in a perspective that focus above all on a specific form of experience (specific structures and intertwining modalities) "that is consistent with 'BPD as currently conceived of." We will try to approach a specific way of living space that fits more in an experiential gestalt than it fits in some strict "labelling" or psychiatric diagnosis, even if this type of lived space is associated with borderline personality disorder (BPD).

\section{Borderline Experience and Lived Space}

\section{Fear of Abandonment and Contact Need - From the} Object Relation to the Lived Distance

If the relational question has always been a central matter in research about borderline people, the main perspective has been the object relation one for a very long time. Since the first developments about the notion of borderline cases, the issue of the separation with the other one (a loved one or an attachment figure) has been essential, and the fear of abandonment has especially been a central topic of discussion.

Psychoanalysis has been the cradle of the borderline notion, and some important authors in this field wrote on the topic. Kernberg wrote about the "ego strength" dimension in relation to the tolerance to the anguish. Bergeret built a theory of "psychic arrangement" (according to which the "borderline astructuration" would developmentally be situated "between" the nevrotic and the psychotic structures) and wrote about the "anaclitic dependency to the object." If we take a look at Winnicott's theories, borderline difficulties are depicted as difficulties to establish transitional space and to create derivatives of such a space, that is, to invest the external object (i.e., the other one) on a symbolic level in order to internalize it. On a developmental level, in Winnicottian theories, the absence or the omnipresence of the "primary object" (e.g., the mother) respectively leads to abandonment or to intrusion anguishes.

Through this review, we can see that the capability to tolerate the absence of the other one, to support being 
alone, or to let the other go is mainly depicted as a capability to internalize a constant and stable representation of the other within "the psychic apparel" (also see Mahler's theorizations). This is based on the idea that the process of remembering and dreaming of the presence of the absent "object" is the key point to lead to a sufficient sense of security. In other words, the failure to support the absence outside is explained by the difficulty to make (or "feel") the other present inside (i.e., in the imagined internal space that is formed by the psychic apparel). There is an outside $\rightarrow$ inside movement that consists in re-presenting.

Let us now deploy 2 clinical excerpts that contain these types of "typically borderline" subjective phenomena and will allow developing an analysis that, in comparison with the traditional psychoanalytical one, will reveal an "other side of the same coin".

\begin{abstract}
Alicia describes her everyday life as a combination of sadness, anxiety and emptiness. When talking about sadness, the first experience she describes is a paroxysmal one, having to do with an emotional gap, that is linked to the feeling of being abandoned or rejected by her boyfriend. This experience is likely to arise during conjugal quarrels or when a threat of breaking-up comes to the fore. With this, abundant tears occur.
\end{abstract}

Alicia says that the fear of abandonment is quite temporary in her life. This fear can occur when Alicia and her partner are physically kept out; for instance, when the partner does not come back at the predicted time or when he is absent for "too long" (for example, when he goes shopping). Alicia talks about a fear, sometimes a temporary conviction, about the eventuality that her partner will never come back. In fact, if an agreement about the reunion time has not been set, Alicia is moping around and becomes more and more anguished over time.

In phenomenological terms, we can notice in Alicia's experience, a predominance of the here-and-now; the concrete, physical distance is the lived distance. There seem to be an excessive load of the material distance which the topological framework precisely allows to properly consider - on lived experience. If the other is absent in the "objective" space, if he is not "tangible," danger appears. The absence of a measurable beacon seems to have great impact. Certain immediacy $[19,20]$ is at work: Alicia fails to feel that the suspension of bodily contact does not imply an extinction of the relationship, with the temporal and spatial enduring dimensions it implies. She fails to consider an end to the moment that is happening, which would enable to consider that new contacts with her beloved one will appear in a new happening, the next situation. A lived time that seems limitless and eternal [21] meets a limitless space.

Let us now glance at Nina's experience.
Generally speaking, Nina explains her permanent need to be in touch, especially with her partner or ex-partners. If an actual contact is not possible, contact is made throughout her smartphone. Solitude, or having few contacts, are frightening to her and make her feel worthless and abandoned. Before and after our interviews, I see Nina continuously texting or being in call.

Nina tells a particular episode that happened a few days ago. While she was in a disco with her girlfriend, she suddenly noticed she could not see her anymore. At the moment, she sent a lot of text messages to her partner, asking her not to abandon her, and was physically violent when they met again. She adds:

"At a given moment, I got lost, I was in (city), I do not know (city), eh, in a disco, there were security guards, eh, they were taller than me, eh, I had the impression that I was a child [...] that I was small, that everybody was able to tread on me, that I was abandoned by my mother."

As we proposed [22], territorialization is closely linked to social matters and to the way the individual integrates the other in one's intimate geography. With regard to that, we can write that Nina seems to ceaselessly tend to make herself present on her (ex-)partners' territory. From that moment on, we can implicitly suppose that Nina fails to feel herself existing in the other's intimate geography and life while not (immediately) being there. On a cognitive and representational level, we could also posit, in contrast to the internalization hypothesis, an externalization hypothesis ${ }^{1}$ : Nina seems to have trouble conceiving the absent territory (as well as the other in herself).

By means of text messages, telephone and video calls, she endeavours to be both present at the place where she currently stands and at another place (with her [ex-]partner) in order to reassure herself. Everything goes as if Nina was struggling against a failure to think, live, and feel herself in the other's proximal geography. Being omnipresent has to prevent the end of the relationship; an ethics of ubiquity seems then to open up regarding phenomena that are commonly viewed as "relational control" behaviours.

In the "disco" episode, we perceive that feeling alone (or more accurately, without her partner in her visual field) provoked a real perdition experience. This geographical perdition that took on the shape of smallness and crushing feelings went hand in hand with a more fundamental insecurity feeling which made the abandon spectrum suddenly reappear. At that moment, Nina saw herself being abandoned.

\footnotetext{
1 Such an hypothesis would implicitly fall back on an internal-representation-invoking theory [23], in that, even if the object of representation would consist in an external reality - i.e., the territory -, representation as an internal process would keep being the considered event.
} 
Intermediary Outcome. Regarding these 2 cases, we may affirm that the borderline patient behaves as if he was ceaselessly feeling kicked out of the territory of the beloved relative. He sees himself potentially leaving the other's life at any moment.

Nina's and Alicia's experiences eventually bring us to conclude with Straus' space of the landscape [24,25]. This type of lived space, which is described as lacking any landmark and any systematization, in which we would get lost, bears an uncanny resemblance to the ones in which Nina and Alicia were immersed when immediately experiencing aloneness and abandonment. It seems that this notion may act as a go-between between the 2 main notions we developed until now, namely, immediacy and ubiquity. Indeed, we can understand how in a "pure feeling" world that precedes crystallization of things as things and just as well formalization of objects and people and of the here and the there $[24,25]$ - we could else write a world characterized by the absence of mediation Kimura [26] underlined when declining different meanings of "immediacy" - a homogenizing-ubiquitarian ambience prevails in which, nothing being nowhere, everything is everywhere. As a matter of fact, space of the landscape, immediacy, and ubiquity appear to be the 3 terms of a unique equation; the equation of the experience borderline people live when being in contact with abandonment-related feelings.

\section{Relational "Ambivalence" and Relational "Tests": Contact Need and Terror of Contact}

When talking about her way of relating to the couple and to men in general (the most problematic domain in her life), the analysis is clear: Alicia is wavering between a certain fear of intimacy and a furious desire to extremely engage in the relationship. The fear is usually prevailing and leads to an attitude made of detachment, mistrust and protection towards men, but when she "drops her guard," Alicia throws herself with all her might in the relationship.

This kind of behavioural ambivalence in relationships (typically the close ones), ${ }^{2}$ that can be related to the wellknown ambivalent-avoiding attachment style, is a redundantly described clinical sign in borderline people. It may lead to relational "tests" that are designed to reassure oneself that the partner is worth an engagement and which sound as rites of passage that do not achieve the objective yet. It may also lead, as in the case of the above-mentioned

\footnotetext{
2 The ambivalence we are writing about has not much to do with the psychoanalytical, nevrotic ambivalence in the sense of the integrated nuance of contrasted feelings.
}

Borderline Personality Disorder, Lived Space, and the Stimmung "disco" episode, to violence. Let us consider this type of experiencing in detail:

The first thing Nina said about herself is that she is a person who tests the boundaries a lot. She explains that she usually "tests" other people, especially in her romantic relationships. These tests may turn out to be verbally or physically violent, as shown by an episode of the day before our meeting, when, being drunk, Nina strangled her partner using a belt, to "see how she was going to react." She adds that she enjoyed the moment. She also mentions an older situation in which she played around the throat of her partner with a machete. The only thing that had permitted to stop this dangerous game have had been a threat of abandonment. Another example of relational test lies in the talks she keeps going with her ex-girlfriends, and that are overtly shown to her current girlfriend. Eventually, the tests can more explicitly relate to the break-up eventuality ("To say that she is not important to me [...] that I am not worth doing anything [...] that there are many girls elsewhere, to see if she stays").

Nina says that all these provocations aim to better take the other back to her, to monopolize this other one, and to possess him. Staying in touch with ex-partners is a constant in Nina's life, and her speech is unequivocal:

"I still have them around me because I still manage to hold all of them. [...] I have this intense fear to be forgotten. [...] As if I wanted to maintain a link. Always. [...] I do not want to place an end."

Nina finally explains that, in her romantic relationships, the separation generally happens. The fear of abandonment can push her into leaving before being left, into committing aggressive acts, or into having hyper-controlling attitudes that encourage the partner to flee. She will also say that, in order to protect herself against abandonment and strong emotions it implies, she aims to dominate to avoid being victimized.

Intermediary Outcome. It seems interesting to refer to Dessoy [27]. This Belgian systemician psychologist wrote about the human milieu (and communities) and used the expression "lived space" to build a part of his theoretical model. He took a spatial viewpoint and introduced 2 organizing spatial themes, considering that every human system has to deal with these themes. These are the themes of fusion and breaking-up. Dessoy also figured a loop (shown in Fig. 1) to underline that movements are occurring between these 2 polarities and that each group finds its own rhythm in the succession of such movements.

In the clinical cases above, the lived distance never seems to be "appropriate": either it is too close [28] or it is too far. We can note a restriction of the areas of lived space [27] in which Alicia and Nina are able to move on. The "passing through" areas, wherein we could observe transitional tendencies between fusion and distance, between unity and difference, seem to have trouble being inhabited. The integration between the 2 main tendencies ap- 
Fig. 1. Ambience loop (own transl.) [27].

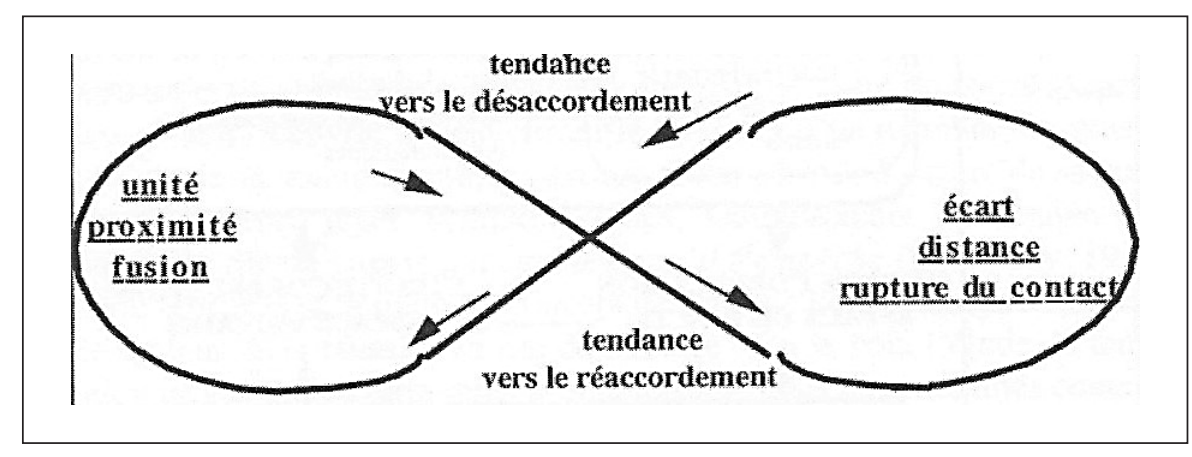

pears to be difficult and a polarization occurs. Hence, even if Dessoy wrote about the characteristics of communities and societies, it could be appropriate to use the concepts he developed to write about the specific phenomenal field that arises when considering organism-environment intertwining in borderline experience.

In this perspective, splitting then appears to be less focused on the "ego" or the "object" as it is in psychoanalytical theories and is more meant to address difficulties in the fluidity of the oscillation concerning relational and social roles (and poles) and topological ways of being-situated.

\section{Auto- and Hetero-Aggressive Behaviours - from the Acting Out Perspective to Specific Lived Worlds}

Non-Suicidal Self-Destructive Behaviours - from the Lack of Mentalization to the Ec-Stasy of a World of Elation

Substance abuse and various addictions, eating disorders (including binge eating episodes), self-injury behaviours, and other various behaviours that may be viewed as comprising some self-destructive dimensions are typical of the everyday life of borderline people.

Traditionally, from a psychoanalytical viewpoint, addiction-related behaviours have been considered in the framework of the object relation perspective. That is to say, authors such as Winnicott, McDougall, or Bowlby have perceived this issue as intimately linked to the quality of primary relationships with the caregivers. Like the fear of abandonment, addictive behaviours have been understood as signs of an exteriority functioning that is tightly linked to a deficiency in the investment of the internal psychic space. Therefore, we have traditionally been in a developmental framework when talking about addiction-related behaviours, and we were never far from convoking anaclitism-related notions. As with fear of abandonment and angry outbursts, a lack of mentalization has been suggested: the transitional object (Winnicott), the protective intern mother (McDougall), or the attachment-related theories (Bowlby) all represent the capability to internalize the protective role of the environment and the security it provides in order to keep functioning on an internal basis ("thinking by oneself") rather than on an external one. The point is that, when being in trouble, the person manages to keep having faith in herself and to exert a daydream capability, thus diminishing the need of acting out or propping up - a need which more clearly involves "external" objects (and a relative "dependency" to them). Self-mutilation has also been incorporated in frameworks that bring to the fore the idea that lacking of possibilities to mentalize (to "psychize") a reality, the self-mutilating subject needs to find the support of a "concrete" (external), physical pain, sensation, or reality.

All these ideas, despite their heuristic value, perpetuate the above-mentioned epistemological backwards. They also implicitly approve a third-person perspective which carries a certain heteronormativity; in that, they lead us to deal with questions that remain unanswered:

- What is the nature of the dependency at stake?

- To what extent is this dependency desirable? When do we begin to consider that the need of the presence of an object becomes an "undesirable" dependency?

- What are the criteria - that can only be moral ones - that allow to promote a specific type of object or dependency and to discourage another one?

In fact, the aforementioned theories seem to take for granted the idea that having no "external" dependency at all is the perfect model. Unlike this perspective, we aim to promote the idea that the only liberty the human being disposes is choosing his privileged dependencies. That is why we are going to try to examine the words of some 
borderline people again, in order to get closer to the everyday lived world of these people, that is to say, to stay in a first-person perspective.

Joëlle says that the triggering factor of scarification episodes is always a guilt-evoking situation. Since she has a strong aversion to this feeling, a very strong anger towards herself comes at the fore. Self-mutilation will enable a tension decrease, and a sort of "waking up." Joëlle seems to set scarifications, alcohol consumption, and bulimic episodes on equal footing as far as effects on lived experience (or psychological functions) are concerned.

"That is something that gets off [...] it relieves tension since we no more have all our reasoning faculties, therefore thoughts are much less intense. [...] And I have the feeling of being drunk."

To Gabrielle, alcohol intakes first aim to calm down: being in a daze and in a euphoric state enables her to forget the problems (we could understand in the same way the fact that Gabrielle often falls asleep after the intake).

We can first notice that the main effect of this kind of behaviours is the tension decrease: when self-mutilating or drinking alcohol, people are calming down (this aspect is included by Rossi Monti and D'Agostino [29] in a function they call dysphoria regulation). In the cases above, it seems to go hand in hand with a suppressing pondering effect.

Surprisingly, with Joëlle, the "back to reality" (or "waking up") function of mutilations is apparently not linked to lived physical pain: Joëlle says she does not feel any pain during the selfharming action. More, she says that she feels nothing.

On the contrary, Gabrielle compares her general suffering with the state of being in a cage from which she cannot escape other than by death or by the ecstasy of pain. She relates a recurrent need to hurt herself and talks about auto-aggressive behaviours (scarifications, burning, tattooing, sexual sadomasochist activities) just as she would talk about drugs.

The question becomes: in which condition do we have to be in order to "manage" to entail our own body without feeling anything, or to precisely seek physical pain? In what way are the self and the world inhabited during the self-harming act? Gabrielle helps us to answer when she adds:

\footnotetext{
"And during a while, when I've hurt myself, I feel... airy. As if I was floating. I am in the total well-being. (...) As if one was taking a line of coke."

"I flout my body since I'm hurting myself. It can be said that my body does not exist, it only exists in order to hurt myself. (...) It becomes a tool, a support in order to hurt myself."
}

The disappearance of sensation and body [21] seems to be extended in a drunkenness dimension that concerns an anaesthesia or a falling asleep that manifests itself either through dizziness (analgesia) or, conversely, through

Borderline Personality Disorder, Lived

Space, and the Stimmung ecstasy of pain. This dimension of lived experience seems to meet what is called by Henniaux [30] "psychic blank" when he points out the fact that in the bulimic crisis, the person does not think herself (does not relate to, or become aware of, herself). Overall, it is a matter of losing oneself in the experience.

Let note that, if it does not seem to arise in Gabrielle or Joëlle's cases, such a "fuzziness" of the embodiment in the lived space can also act as a trigger to self-harming acts that, from then on, will aim to feel oneself again. In comparison with the previous description, triggering factors and effects appear then to be inverted, illustrating one more time how the instability in the embodiment [31] can express itself in borderline experience.

Immediacy and Community. Let us examine Gabrielle's experience again and discover what type of lived world can be implied by this sort of behaviours.

Apart from calming down, alcohol and cannabis consumption fulfil a second function in Gabrielle's life. Actually, if Gabrielle drinks during festive moments, it is above all to be in the same atmosphere than others. She also explains that she is more receptive to the good mood and to humour when drinking. "When everybody laughs, we laugh with," she says. Without alcohol or marijuana, Gabrielle stays in her "gloomy bubble," her "natural state," within which she suffers, feels downhearted, "outside of time," and "asocial." She eventually describes that, without consuming, she would not lie "in the same world" than people around her. Countering boredom and shyness are also mentioned by Gabrielle as functions of the consumption, but seem to be included in the "atmosphere" one.

In a word, thanks to alcohol and marijuana, Gabrielle feels more extrovert... that is to say, more directed towards an outside-of-oneself. Charbonneau [32], when writing about addictions and dependent personalities, alludes to the entrapment-elation dialectics to describe inebriation. He postulates that every addiction originates in micro-tensions that are calling for release. These tensions (that we concretely feel as restlessness, waiting, boredom, need of action, or else, lifelessness) are gripping the person, where Charbonneau thinks the function of every inebriation is to loosen and release. In fact, posing that an intersubjective background is always supporting experiential phenomena, he incorporates the entrapment-elation dialectics in a more fundamental "usness." As such, the entrapment appears to be an element that separates from, while the loosening dimension of elation appears as a sketch of fusion with what we were separated from. That is why Charbonneau finally considers the elation that is provoked by the inebriation as a call to community/collectivity, that is, to a general "Other." 
These developments appear to echo Gabrielle's experience: Gabrielle drinks to be-with and perceives alcohol consumption as being, by definition, a group activity. $\mathrm{Cu}-$ riously, Gabrielle was the one whose discourse referred the most to the "common thing" and to the "We" pronoun, and talked about herself in the name of borderline people. This tendency has again been proven when observing the strong solidarity Gabrielle showed towards other patients in the hospital during informal moments. Everything is happening as if an enlargement of the lived world, that is to say, a sort of horizontal expansion in the space, was relieving a felt entrapment.

Intermediary Outcome. The return to immediacy as an absence of mediation, as something that "pre-dates the verbal-discerning determination" ([26], also see [19, 33]), appears now in the sense of a propensity to come back to an undifferentiated common space (or Kimura's "original intersubjective aïda") that enables to understand bulimic crises, scarification episodes, and drug consumption in Joëlle and Gabrielle. This propensity seems to give meaning both to the usual gathering of the different types of self-destructive behaviours we studied in this part of the article and to the more general gathering of the so-called heterogeneous symptoms of Borderline Personality Disorder. It also opens up perspectives to concretely think of the authenticity value Mancini and Stanghellini [34] mention as an important need, in borderline people, of absolute emotional fusion with the other (including oneself as another one).

Lived Distance and Angry Outbursts - From the Acting Out to the "Seeing Red" Ec-Stasy of a WorldTo-Destroy

Hetero-aggressive acts are another important topic. In particular, angry outbursts are another quite typical manifestation in borderline people.

From a psychoanalytical viewpoint, such incidents are generally interpreted in a way that brings to the fore the victory of the pleasure principle over the reality principle or of the primary mental processes over the secondary ones. The point is the difficulty to inhibit the drive (which is coming from inside), to postpone the "shot," the satisfaction. In the same line, another classical way of analysing the issue will consist in invoking castration and a defect in the internalization of it, dealing with the Superego and the renunciation questions. In the final analysis, acting out is used most of the time to talk about the angry outburst as a result of a lack of mentalization. These ideas, which keep being of great relevance for the clinical practice, present the main dis- advantage of implicitly admitting the inner/outer scission we highlighted above ${ }^{3}$ and, more generally, the topographical framework.

Trying to engage in a more topological and ecological perspective to complement previous hypotheses, we are brought to discover that, during these explosive episodes, a particular lived world is at work.

During the fits of anger, Gabrielle hits and destroys objects, throws them toward the person with whom she is angry, shouts at her in order to be heard, and to "exteriorize" her own rage.

"I do not manage to restrain myself anymore, I no longer have any limit. I am enraged. I am not myself anymore. I am somebody else, a violent one, an enraged one, that nothing would stop.

(...) Adrenaline is at its best, I could be hit, I do not feel anything. I do not feel pain anymore, I no longer feel anything. I really am in a 'total crisis' state."

(Experimenter: "Do you feel your body in a particular way, at that moment”?)

"Yes. A strength. And at the same time, [...] like a veil in front of my eyes (Experimenter: A veil...) As if... I do not know how to explain, I am not myself, so I feel that... These are not my eyes, these are other eyes. (Experimenter: And how are these 'other eyes'?) Oh... blind. Because I am in a rage, so I see nothing, I do not see what I am doing. (Experimenter: And what do you see, if not what you are doing?) That is difficult to explain... I just see in my gestures, I just see in my head what I have to do, so, I see that I have to throw thingies, that I have to scream, that... These are the only things that lie around in my head; screaming, blowing a fuse, throwing thingies, eh, there are the only things that I see. Any object, anything within easy reach is caught and thrown. (Experimenter: And the other one, how do you see him, at that moment? The other person.) My partner, for instance? (Experimenter: Yes, for example.) Like an enemy. That has to be annihilated. Like a monster. [...] We want to hurt the other, just as much as he hurt us. [...] You hurt me, so... I do not know, it is difficult to put words on that, that is more than being blind because we want to exteriorize the ache we just got, and at the same time... we do not manage to do so, so we want to hurt, one way or another."

Being somebody else, being "possessed," goes hand in hand with an "enraged" confusion that reminds a locution that Gabrielle often used:

"At the time, I am seeing red."

In Gabrielle's lived world, at this moment, anger ecstasy seems to go hand in hand with a "fuzzy" atmosphere, a blindness sensation, and dissociative experiences that the common locution "being beside oneself" literally seems to grasp.

3 For a first phenomenological approach of the lack of mentalization as a hypo-reflexivity which is not landlocked in the limits of an inner psychic life model, see [19]. Also see [35]. 
Gabrielle's words, besides their relation to aggressiveness, indicate a change of world. The world is here coloured in a particular way; there is a shift and the violent move, when begun, cannot be stopped. If fuzziness prevails, one thing is clear: space, made of a targeted other and of objects, is lived as a hostile world made of revenge and reprisal. The other is nothing more than the otherthat-hurt-me and the other-that-I-have-to-annihilate. ${ }^{4}$ $\mathrm{He}$ is nothing more than an additional element of the landscape that has to be wiped out.

So, it seems that perceiving the other as an enemy to beat and a monster to annihilate, enables the borderline person to temporarily have some "clear" representations she typically lacks and that contrasts with the ambient confusion that is simultaneously lived. There is thus the clarifying power of anger on representations described by Stanghellini and Rosfort [20].

Furthermore, beyond clarity and direction it provides for the hate to move on (the instinctual movement finds a "clear" object to invest), this phenomenon also gives clear targets and means for action: beating the enemy, breaking things, and throwing objects. In other words, this particular way of perceiving the other goes with an experiencing of a world-to-transform, a world-to-destroy.

Intermediary Outcome. To summarize, it seems that a specific experiential-perceptual attitude towards the very material space emerges, which lets no doubt about the type of intertwining organism/environment field that is at work. The stimmung is here composed of an all-encompassing feeling of "being outside of oneself" that curiously takes us back to the etymological meaning of "ecstasy," and of clear features for specific perceptions and actions in this fog, i.e., hating and destroying.

In the ec-stasy of anger, we interestingly notice the forgetting oneself and the enlargement of the space again, that were, in the previous section, constitutive of the elation of drug consumption and of the ec-stasy of pain/anaesthesia in scarification and bulimic episodes.

\section{Waning of Reflexivity in the Lived Space.}

\begin{abstract}
Alicia talks about hetero-aggressive episodes:
"That is a fuse that blows. [...] A hose that trips. [...] A switch. [...] I am not able to descend that process (the reasoning one). [...] But deep down inside myself, I feel that I am doing something wrong. [...] There is not any reasoning faculty anymore. [...] I come back down to such a primal level. [...] I am grasped so much by the emotion that... I cannot help myself."
\end{abstract}

\footnotetext{
4 Let note the still valid heuristic and clinical value of the psychoanalytical 'object splitting' mechanism.
}

Borderline Personality Disorder, Lived Space, and the Stimmung
Alicia also relates a particular episode. Not long ago, while she was assaulting her boyfriend, the fact that he took his mobile phone out to film her suddenly enabled Alicia to stop. She explains this "success" by the fact that the video clip was forming a piece of evidence of her acts and of what they involve in terms of behaviour ("Look at the horrible person you are").

In this excerpt, it appears that, during angry outburst, Alicia really seems to be absorbed by the immediate emotion. This invasive emotion does not allow Alicia to exist in her entirety anymore: exercising reflexivity, as a prerequisite condition for self-determination, is not possible anymore. So, it seems that the fusion-with-the-space we already described with Gabrielle is still valid here but in another way.

We also notice what enables Alicia to become an agent of her acts again and to direct these again towards a more ego-syntonic perspective (non-violence figures among her most important values): the objectivation of her-being-violent by an external agent and so the becomingaware-of-herself by the means of a third-person perspective.

Experiencing that an "objective" look was fixing upon her led Alicia, in turn, ashamed, to look at herself; that is, to leave the "fusional," undifferentiated atmosphere in order to self-reflect. We can also affirm that a mirror phenomenon was at work. The act of realizing seem to reveal, ad absurdum, a preceding alteration of self-consciousness in the lived space.

Intermediary Outcome. To sum up, the temporary difficulty to get to reasoning and the sudden stop of violence that was allowed by the specular phenomenon allow us to suppose, retrospectively, a link between the tyranny of immediacy (and the fusion and elation that are inherent to it) and a waning of reflexivity in the lived space.

\section{Conclusion: Borderline Experience, Lived Space, and the Stimmung}

The phenomena we unfolded in this contribution, if taken one by one, should not be considered borderlinespecific manifestations. We take for granted that everyone can experience these phenomena. However, all things considered, when taking lived experience into account, a specific gestalt seems to emerge. Neither the self-mutilations, nor the addiction behaviours or the fear of abandonment and so forth, in themselves, have seemed to hallmark borderline experience. The fact remains that a certain type of composite picture, made of several of these 
manifestations that are linked by or integrated in a specific type of stimmung (atmosphere), can be considered a typical organizer of borderline experience. In fact, we can also say that everyone can experience it, but that in the case of borderline people, this experience is lived with a stronger intensity, at a higher frequency, and with more rigidity. Then, as often happens in psychopathology, what is described here relates to phenomena that are part of the general human experience but are lived with some variations.

As we already knew [20,36-38], fear of abandonment, self-destructive behaviours, hetero-aggressive crises, and so forth seem to embed themselves in a background experience made of a specific sort of depressivity. This chronic dysphoric state is established by emptiness and inanity feelings, diffuse tension, and a thirst of life that leads to a disordered and desperate vitality $[18,39$, 40]. Thanks to our study, it seems that we can now complete this picture. Actually, we learnt that the everyday experience of some borderline-diagnosed people also appears to be constituted by a profound embeddedness of experience in ubiquity and immediacy, important difficulties to move on between the poles of unity and difference, and a quite horizontal concern with elation and ecstasy. The latter takes on various shapes and enables a specific sort of social contact by involving a forgetting oneself that has to do with a certain kind of waning of reflexivity in the lived space. These various atmospheric dimensions seem to constitute the different facets of a global experience.

It seems that, in addition to the psychoanalytical and topographical classical hypotheses, that focus on the (un)conscious paths by which some inner excitants and psychic stuff determine the borderline condition, we can now dispose of a better understanding of what the everyday world of the borderline person is made of. We can grasp the type of ambiences certain symptoms can elicit or out of which they can emerge, whether it is before, during, or after the symptom deployment. In other words, we can add to the ultimate causes of BPD that psychoanalysis described, some of the functions and sensations that accompany this so-called gathering of behaviours. In line with Fuchs' [8] assumption that the question "Who am I?" is inseparable from the question "What is the world like in which I live?", we can now approach what it is like to be a borderline person, that is to say, to live borderline moments, or else, to live in a borderline world during some moments.

Then, if we consider that one of the main goals of phenomenological psychotherapy is "to enter and to share the world of the other" [8], this contribution may bring some elements to help us achieve this task, as long as we keep in mind that no life, no singular experience can fit with any theory.

\section{Statement of Ethics}

This study protocol was approved by the Ethics Committee of the Liege University Hospital Center (Belgium), approval number 2017-267. Subjects have given their written informed consent both to participate in the study and for the data to be used for research purposes.

\section{Conflict of Interest Statement}

The authors have no conflicts of interest to declare.

\section{Funding Sources}

The authors have no funding sources.

\section{Author Contributions}

Fabian Lo Monte made substantial contributions to the conception and design of the work; collected, analysed, and interpreted data; drafted the work; approved the final version; and agrees to be accountable for all aspects of the work in ensuring that questions related to the accuracy or integrity of any part of the work are appropriately investigated and resolved. Jérôme Englebert made substantial contributions to the conception and design of the work, revised the work critically for important intellectual content, approved the final version, and agrees to be accountable for all aspects of the work in ensuring that questions related to the accuracy or integrity of any part of the work are appropriately investigated and resolved.

\section{Data Availability Statement}

All data generated or analysed during this study are included in this article. Further enquiries can be directed to the corresponding author. 


\section{References}

1 Englebert J. Ubiquité et situation: pour une considération topologique de la limite. Le Cercle Herméneutique. 2017;28:71-5. magazine.

2 Freud S. Abrégé de psychanalyse. Paris: Presses Universitaires de France; 1938.

3 Cancrini L. L'océan borderline : troubles des états limites, récits de voyage. Louvain-laNeuve: De Boeck; 2009.

4 Bachelard G. La poétique de l'espace. Paris: Presses Universitaires de France; 1957.

5 Minkowski E. Le temps vécu. Paris: Presses Universitaires de France; 1933.

6 Merleau-Ponty M. Phénoménologie de la perception. Paris: Gallimard; 1945.

7 Fuchs T. Ecology of the brain: the phenomenology and biology of the embodied mind. Oxford: Oxford University Press; 2018.

8 Fuchs T. Psychotherapy of the lived space: a phenomenological and ecological concept. Am J Psychother. 2007;61(4):423-39.

9 Fuchs T. The interactive phenomenal field and the life space: a sketch of an ecological concept of psychotherapy. Psychopathology. 2019;52(2):67-74.

10 Westen D. The scientific legacy of Sigmund Freud: toward a psychodynamically informed psychological science. Psychol Bull. 1998; 124(3):333-71.

11 Wykretowicz H. La sentinelle silencieuse: recherches phénoménologiques sur l'incarnation de l'esprit et perspectives cliniques. Paris: Hermann; 2021.

12 Gallagher S. Enactivist interventions: rethinking the mind. Oxford: Oxford University Press; 2017.

13 Blaize J. Ne plus savoir: phénoménologie et éthique de la psychothérapie. Libourne: L'exprimerie; 2001.

14 Lewin K. Principles of topological psychology. London: McGraw-Hill; 1936.

15 Heidegger M. Être et temps. Paris: Gallimard; 1927.

16 Bégout B. Le concept d'ambiance. Paris: Seuil; 2020.

17 American Psychiatric Association. Diagnostic and statistical manual of mental disorders. 5th edn. Arlington: American Psychiatric Association; 2013.

18 Ratcliffe M, Bortolan A. Emotion regulation in a disordered world: understanding borderline personality disorder. In: Stanghellini G, Tewes C, editors. Time and body: phenomenological and psychopathological approaches. Cambridge: Cambridge University Press; 2021. p. 177-200.

19 Lo Monte F, Englebert J. Borderline personality disorder and lived time. Évol Psychiatr. 2018;83(4):e37-45.

20 Stanghellini G, Rosfort R. Emotions and personhood: exploring fragility-making sense of vulnerability. Oxford: Oxford University Press; 2013.

21 Englebert J, Follet V. Personnalité borderline et tatouage: hyppolite et le corps-en-disparition. Cah Psychol Clin. 2018;1:231-48.

22 Englebert J. Psychopathologie de l'homme en situation: le corps du détenu dans l'univers carcéral. Paris: Hermann; 2013.

23 Zahnoun F. On representation hungry cognition (and why we should stop feeding it). Synthese. 2021;198:267-84.

24 Straus E. Les formes du spatial. In: Courtine J-F, editor. Figures de la subjectivité. Translated by: M. Gennart: Paris: CNRS; 1992. p. 15-49. (Original work published 1966).

25 Gennart M. Une phénoménologie des données hylétiques est-elle possible? Etudes Phénoménol. 1986;2(4):19-46.

26 Kimura B. Écrits de psychopathologie phénoménologique. Vendôme: Presses Universitaires de France; 1992.

27 Dessoy E. Vers une organisation du milieu humain. I: de l'intérêt du concept de « milieu » en psychothérapie institutionnelle et en approche systémique. Thér Fam. 1993;14:311-30.

28 Fineberg SK, Leavitt J, Landry CD, Neustadter ES, Lesser RE, Stahl DS, et al. Individuals with borderline personality disorder show larger preferred social distance in live dyadic interactions. Psychiatry Res. 2018;260:38490.

29 Rossi Monti M, D’Agostino A. Abnormal bodily experience in borderline personality disorder: clinical issues and psychopathological perspectives. Clin Neuropsychiatry. 2016; 13:37-42.

30 Henniaux M. Le fonctionnement du corps dans les troubles des conduites alimentaires. Inf Psychiatr. 2009;85(1):35-41.

31 Schmidt P. Nobody? Disturbed self-experience in BPD and four kinds of instability. In: Tewes C, Stanghellini G, editors. Time and body. Cambridge: CUP; 2021. p. 206-29.

32 Charbonneau G. Introduction à la psychopathologie phénoménologique: tome I. Paris: MJW Fédition; 2010

33 Muscelli C, Stanghellini G. Istantaneità: cultura e psicopatologia della temporalità contamporanea. Milan: FrancoAngeli; 2012.

34 Mancini M, Stanghellini G. Values in persons with borderline personality disorder: their relevance for the therapeutic interview. Res Psychother. 2020;23:449-55.

35 Koster A. Mentalization, embodiment, and narrative: critical comments on the social ontology of mentalization theory. Theory Psychol. 2017;27(4):458-76.

36 Pazzagli A, Rossi Monti M. Dysphoria and aloneness in borderline personality disorder. Psychopathology. 2000;33:220-6.

37 Rossi Monti M, D’Agostino A. Dysphoria in borderline persons. In: Stanghellini G, Raballo A, Broome M, Fernandez AV, Fusar-Poli P, Rosfort R, editors. The oxford handbook of phenomenological psychopathology. Oxford: Oxford University Press; 2018. p. 827-38.

38 Rossi Monti M, D’Agostino A. Borderline personality disorder from a psychopathological-dynamic perspective. J Psychopathol. 2014;20:451-60.

39 Stanghellini G, Rosfort R. Borderline depression: a desperate vitality. J Conscious Stud. 2013;20:153-77.

40 Stanghellini G, Mancini M. The life-world of persons with borderline personality disorder. In: Stanghellini G, Raballo A, Broome M, Fernandez AV, Fusar-Poli P, Rosfort R, editors. The oxford handbook of phenomenological psychopathology. Oxford: Oxford University Press; 2018. p. 665-81. 